\title{
Application of Order Analysis to Diagnose Fatigue within Wind Turbine Gearbox
}

\author{
Abdulwahed Salem $^{1} \cdot$ A. Abu-Siada ${ }^{1} \cdot$ S. Islam ${ }^{1}$
}

Received: 8 August 2016 / Accepted: 5 December 2016 / Published online: 20 January 2017

(C) Crown Copyright as represented by Curtin University 2017

\begin{abstract}
One of the most expensive and critical component in wind turbines is the gearbox. Gearbox failure may have significant impacts on the network in terms of continuity of power supply especially in islanded areas where the majority of power demand is supplied by wind farms. As such, an effective condition monitoring technique for wind turbine gearbox should be adopted to avoid any catastrophic failure to the gearbox and maintain system reliability. This paper presents a technique to monitor the gearbox condition through monitoring the shaft torque and the gearbox vibration signals. Practical measurement is conducted on a test rig that emulating real wind turbine operation. Model based control technique using voltage slider by injecting a current through the induction generator stator terminals is applied to emulate real fault conditions on the wind turbine blades such as icing accumulation, wind share and gust wind. Order analysis technique is used to analyse and compare the obtained signals during normal and abnormal operating conditions.
\end{abstract}

Keywords Wind energy · Condition monitoring · Gearbox $\cdot$ Bearings $\cdot$ Blades

\section{Introduction}

Due to the degradation and cost increase of conventional fossil fuel along with the global trend to decrease the

Abdulwahed Salem

a.salem@postgrad.curtin.edu.au

1 Curtin University, Perth, Australia greenhouse effect, clean energy production from renewable sources has been given a great concern during the last few decades. Owing to the rapid increase in wind energy conversion systems (WECS), wind turbine condition monitoring has recently attracted many researchers proposing several techniques to detect incipient mechanical and electrical faults to avoid any possible catastrophic failures. Improvement of the mechanical strain of the wind turbines is achieved by applying direct control to the induction generator electromagnetic torque [1]. Failure of specific wind turbine component such as blades, gearbox, breaking system and tower may lead to a catastrophic failure jeopardizing the whole investment $[2,3]$. The propulsive forces resulted from wind speed variation that the WT rotor faces during operation have a significant impact on the lifespan of the WT. Many techniques have been published in the literature to monitor the wind turbine drivetrain to explore incipient faults in order to allowing effective maintenance scheme. Various gearbox failures have been investigated in the literature [3]. Thiringer and Linders focused on the control a wind turbine with fixed pitch angle through controlling rotor speed [4]. Combet and Gelman [5], studied the sideband ratio features to check gear health condition. Generally, in order to investigate the failure root causes and monitor the health condition of WT components, researches count on examined characteristics. Critical loads result in passive effect on the gearbox and may produce nonlinear transmission path and disturbances to the vibration signal [6]. In cold weather and at low wind speed due to wind share, one of the common problems facing the wind turbine blades is the leading edge ice accretion [7]. Even with the presence of anti-icing systems, ice accretion can still have a negative impact on the overall performance of the wind turbine as discussed in [6,7]. Many countermeasures have 
been discussed in the literatures such as countless shapes of leading edge icing, trailing edge icing and blade surface icing. Paring down blades problems will lead to the reduction of the blade size [7]. Two types of vibration are affecting the blades; flabwise and edgewise, the last mode has significant apprehension on wind machines as a result of the violent vibrations [8]. Figure 1 illustrates failure modes and the corresponding downtime of WECS according to studies provided by different companies (WMEP and LWK) during 13 years [9]. From the figure, it can be observed that gearbox, rotor blades and drive train failures cause significant downtime to the whole WECS. Authors of $[10,11]$ reveal that $59 \%$ of wind turbine failures are related to the gearbox. Industrial gears failures and fault diagnosis has been given a great attention by researchers $[12,13]$. Gearbox is a key element in wind turbines condition monitoring due to its challenging accessibility, complexity design and dynamic operating conditions. When a wind gust hits the rotor, blades movement can cause a temporary misalignment between the two shafts connected through the gearbox [14]. This may lead to a decay on the bearing loads and minimize lifespan of the wind turbine [2]. Authors of [15, 16] categorised the common gear failures into two types of stress; contact stress and root bending stress. The former causes gear pitting and the later causes tooth crack or tooth damage. Both types can lead to premature gear wear and failure. This paper introduces a technique for gear box condition monitoring using order analysis that has been commonly used in analysing signals especially in gear rotating machines [17], speed and tracking specific harmonics related to the faulty component. Fault diagnoses and the detection of failure mode is a fundamental aspect of any successful maintenance procedure. Different failures modes require different detection techniques and diagnoses strategies to detect any potential failure as soon as it emerges. Order analysis is one of the diagnoses analysis techniques suitable for tracking the machine's health condition. Fluctuating load and deformity in the rotating machines cause constrained vibrations. By involving spectra and time histories, with the speed of the moving parts, order analysis can detect the vibration of fluctuating loads, critical speeds, and unstable actions [18]. A comprehensive discussion and further detail, including the strengths and limitations of the order analysis technique, are presented in [19, 20].

\section{Experimental Setup}

In this section, the hardware set-up used to conduct the experimental measurements is presented.

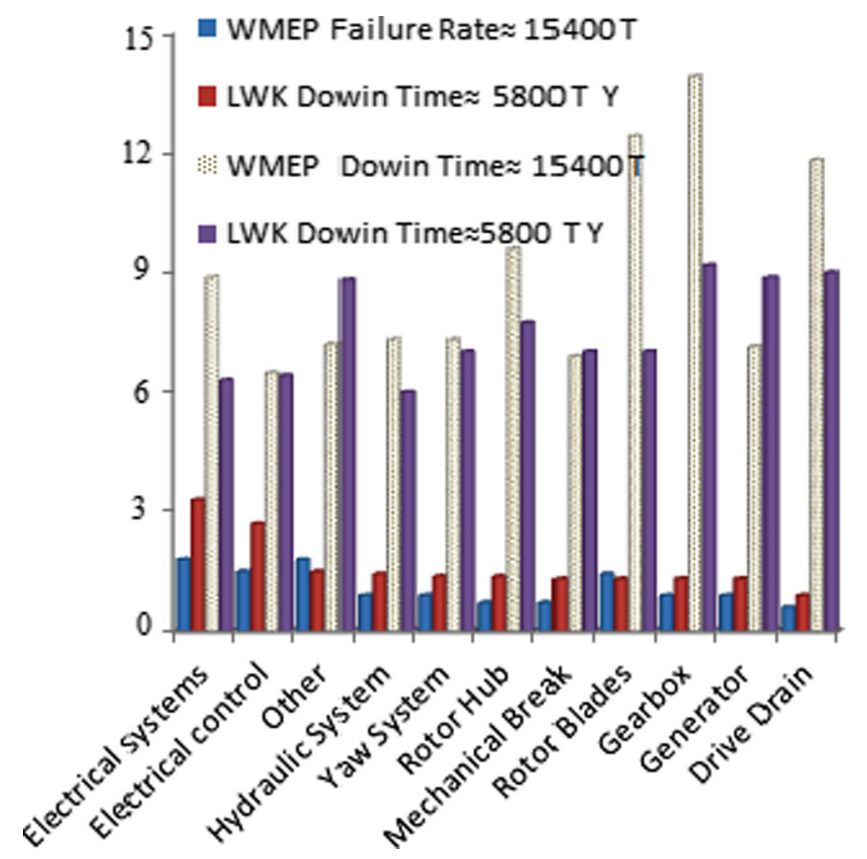

Fig. 1 Downtime per failure/year

Figure 2 shows a schematic diagram for the test rig used for experimental measurements. The test rig consists of an induction motor connected to a gearbox through a shaft and coupling system to the generator. Numbers of high resolution accelerometers of low $(0.1 \mathrm{~Hz})$ and high $(1000 \mathrm{~Hz})$ frequency with sensitivity of $\pm 10 \%$ are installed on the drive train at different locations to collect the vibration signals. The two stage helical gearbox (type NHL25) with a ratio of 1:4.34 is lubricated with mineral oil SOVG 220. Torque transducer is fitted between the prime mover and the

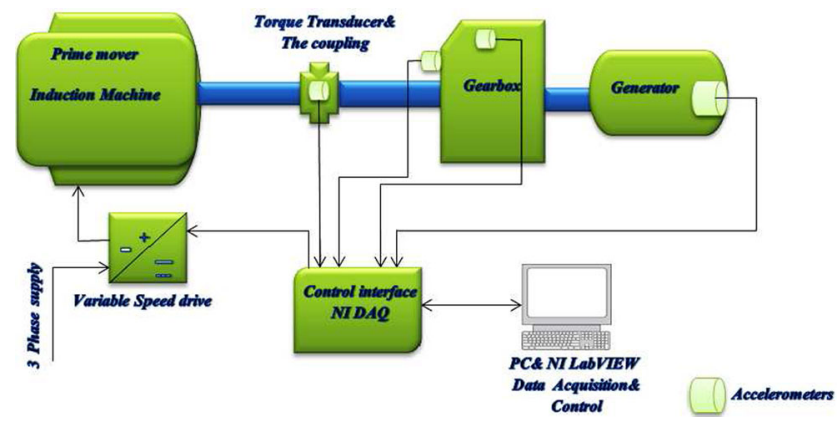

Fig. 2 Test Rig setup of the drive train of wind turbine 
Fig. 3 Torque signal recorded with normal operating condition

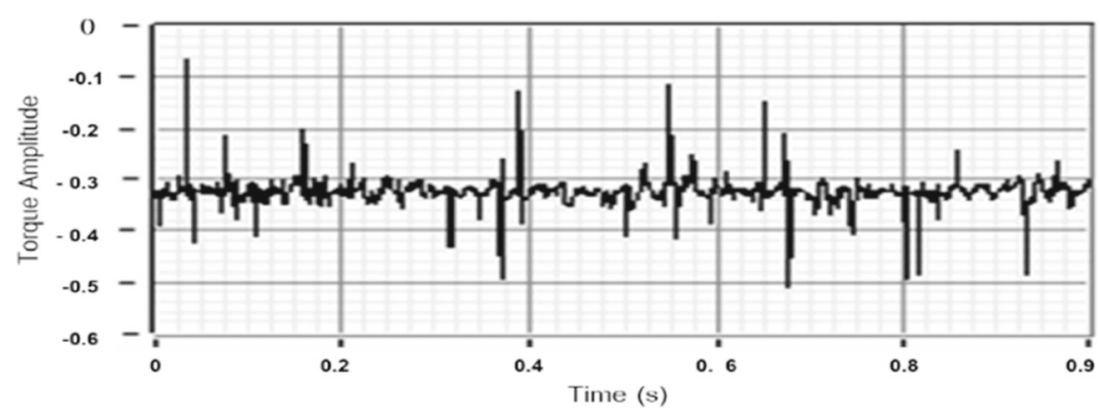

low speed shaft of the gearbox. Measured data are collected using high quality accelerometers with high sampling rate in order to detect small fluctuations with more details.

\section{Test Rig Results}

The most significant reflection is not the speed of response, as the high subsidence of the rotor is not capable to follow the fast changes of the wind, but tracking the fluctuating of the frequency response of the drivetrain phenomena. These conditions are motivated by wind variations, along with the torque harmonics and result in continued mechanical stress affecting the WT efficiency. The torque signal is extracted from the sensors fitted on specific locations on the gearbox of the WT as shown in Fig. 2. Figure 3 shows the torque of the main shaft at rotor speed of $200 \mathrm{rpm}$ with the system at no load and normal operating conditions. Mechanical stress on the rotor shaft was applied using a stator injection current of $5 \mathrm{~A}$ to establish an opposite electromagnetic torque on the shaft which reflects the real condition that the WT facing in real life. The torque signal for stressed rotor shaft is recorded as shown in Fig. 4. This figure shows how the mechanical stress significantly changes the torque magnitude which may lead to life fatigue to the drive train of the WT due to the high torque magnitudes. Vibration sensors are also fitted to extract the vibration signature during normal and stressed shaft conditions. These signals are then analysed using order analysis technique as shown in Figs. 5 and 6 , respectively. Figure 5 reveals that the vibration signal exhibits high amplitude of harmonics up to $5^{\text {th }}$ order as can be shown in the harmonic spectrum of Fig. $5 \mathrm{~b}$ and c. A significant change in the Order spectrum and the power spectrum is clearly observable when a stress is emulated by injecting $8.5 \mathrm{~A}$ through the generator stator terminals which cause more stress on the drive train.

Increasing the stress on the generator shaft by increasing the injected current to $8.5 \mathrm{~A}$ through the stator terminal windings, will lead to a further decrease in the power spectrum magnitude and harmonic contents as can be seen in Fig. 7. This could leads to high bearing temperature and accelerates the aging of lubrication oil which may lead to hot spots within the gearbox and to mechanical failure to the drivetrain of the wind turbine. If such stresses are not attended on time, there will be a high chance to disconnect the WT from the grid causing interruption to
Fig. 4 Torque signal recorded at $200 \mathrm{rpm}$ with faulty operating condition that is emulated by injecting $5 \mathrm{~A}$ at the generator stator terminals

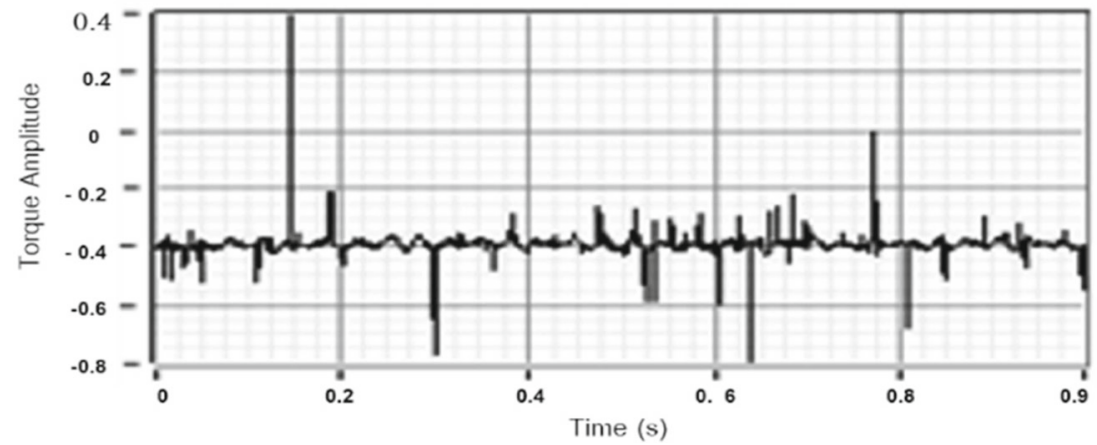



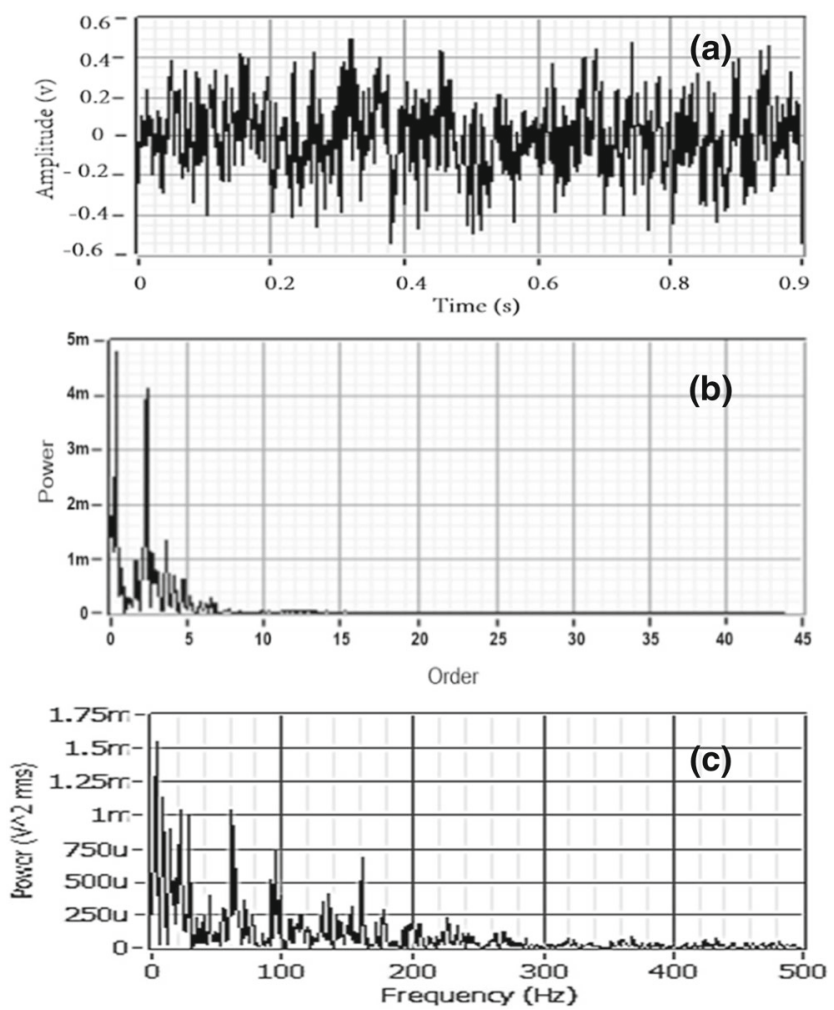

Fig. 5 Signals conducted under normal operating condition (healthy conditions)
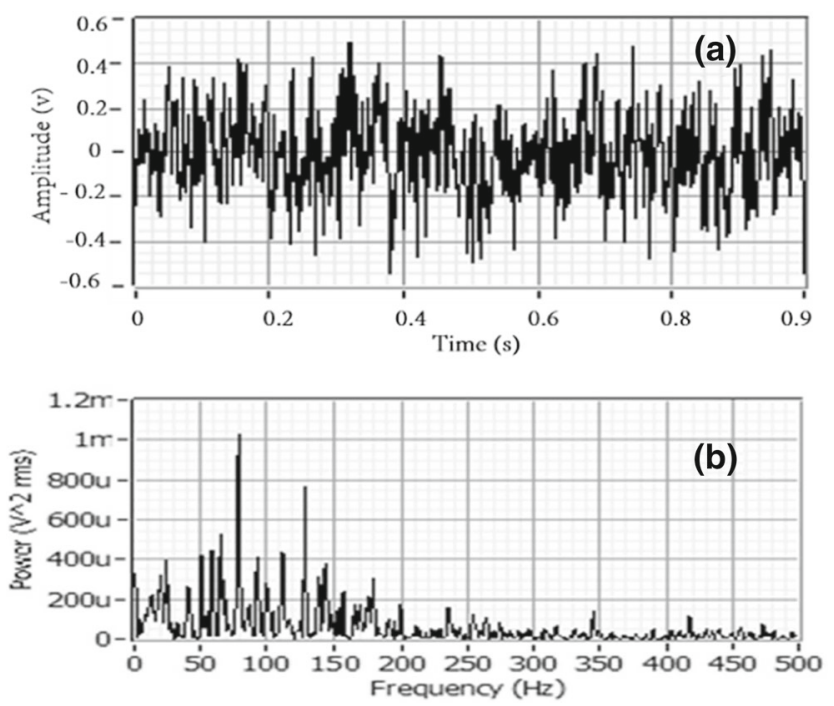

Fig. 6 Signal with applied stress (faulty operating condition) that is emulated by injecting $7 \mathrm{~A}$ at the generator stator terminals
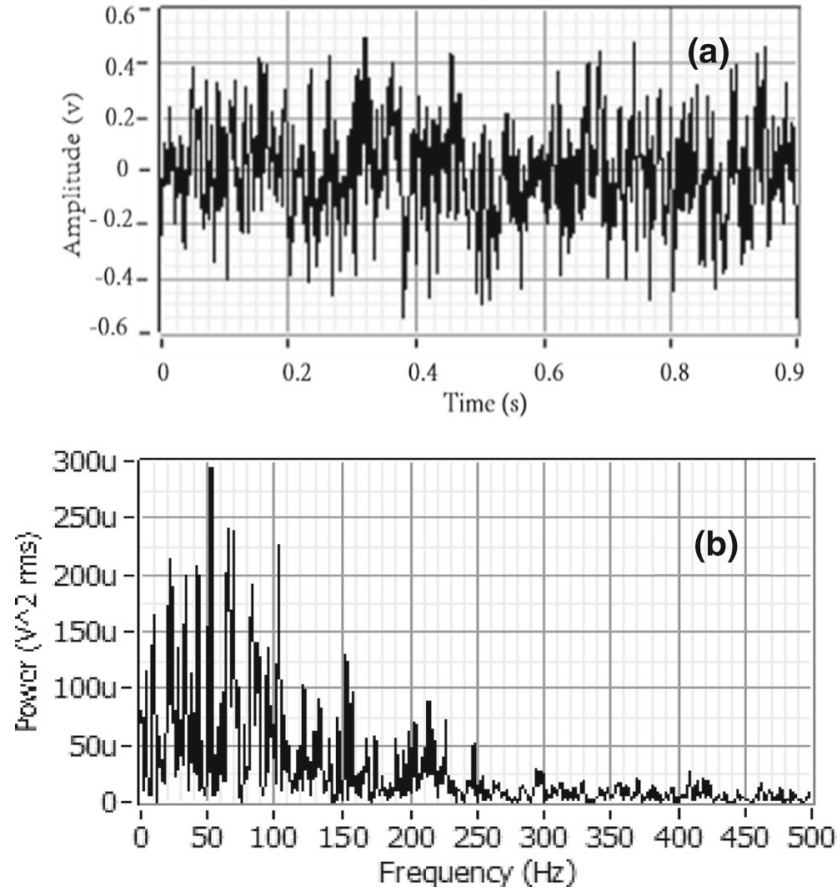

Fig. 7 Signals conducted under more stress (faulty operating condition) that is emulated by injecting $8.5 \mathrm{~A}$ at the generator stator terminals

the electricity supply and high maintenance or replacing costs.

\section{Conclusions}

This paper presents an experiment study to emulate wind turbine operation. The dynamic forces generated by wind gust as an example will not only affect the turbine blades but will also have a direct impact on the internal drivetrain components. The common shaft torque signal is used to monitor the health condition of the gearbox connecting the turbine which is represented by an induction motor to the generator. A mechanical stress was applied to the shaft by injected currents through the generator stator terminals to simulate some environmental harsh conditions such as gust wind and ice accumulation on the wind turbine. The recorded torque signal is analysed using order analysis to decompose its harmonic contents. Results reveal that, mechanical stress on the shaft will lead to a significant increase in the torque signal that will also experience more harmonics during abnormal operating condition. On the other side, vibration signature exhibits a reduction in its harmonic spectrum when the shaft is more stressed. This technique could be used to monitor the health condition of the mechanical system of the wind turbine as it is simple, easy to implement but yet effective in detecting any incipient abnormality in the system. 
Acknowledgments The work presented in this paper is part of an on-going research project. The authors would like to thank Curtin University Postgraduate Student Association (CUPSA) for giving support to Higher Degree Research (HDR) students.

\section{References}

1. Molinas M, Suul JA, Undeland T (2010) Extending the life of gear box in wind generators by smoothing transient torque with STATCOM. IEEE Trans Ind Electron 57:476-484

2. Salem A, Abu-Siada A, Islam S (2013) A review of condition monitoring techniques of the wind turbines gearbox and rotor. International Journal of Electrical Energy 2(1):53-56

3. Kar C, Mohanty A (2006) Monitoring gear vibrations through motor current signature analysis and wavelet transform. Mech Syst Signal Process 20:158-187

4. Thiringer T, Linders J (1993) Control by variable rotor speed of a fixed-pitch wind turbine operating in a wide speed range. IEEE Trans Energy Convers 8:520-526

5. Combet F, Gelman L (2011) Novel adaptation of the demodulation technology for gear damage detection to variable amplitudes of mesh harmonics. Mech Syst Signal Process 25:839845

6. Lei Y, Kong D, Lin J, Zuo MJ (2012) Fault detection of planetary gearboxes using new diagnostic parameters. Meas Sci Technol 23:055605

7. Ozgener O, Ozgener L (2007) Exergy and reliability analysis of wind turbine systems: a case study. Renew Sust Energ Rev 11:1811-1826

8. Staino A, Basu B, Nielsen SR (2012) Actuator control of edgewise vibrations in wind turbine blades. J Sound Vib 331:1233-1256
9. Sheng S, Yang W (2013) Wind turbine drivetrain condition monitoring-an overview (presentation). National Renewable Energy Laboratory (NREL), Golden, CO

10. Link H, LaCava W, Van Dam J, McNiff B, Sheng S, Wallen $\mathrm{R}$ et al (2011) Gearbox reliability collaborative project report: findings from phase 1 and phase 2 testing. Contract 303:2753000

11. Astridge DG (1989) Helicopter transmissions-Design for safety and reliability. Proceedings of the Institution of Mechanical Engineers, Part G: Journal of Aerospace Engineering 203:123-138

12. Wang W, McFadden P (1993) Early detection of gear failure by vibration analysis i. calculation of the time-frequency distribution. Mech Syst Signal Process 7:193-203

13. McFadden P (1987) Examination of a technique for the early detection of failure in gears by signal processing of the time domain average of the meshing vibration. Mech Syst Signal Process 1:173-183

14. Ciang CC, Lee J-R, Bang H-J (2008) Structural health monitoring for a wind turbine system: a review of damage detection methods. Meas Sci Technol 19:122001

15. Li S (2013) Effects of centrifugal load on tooth contact stresses and bending stresses of thin-rimmed spur gears with inclined webs. Mech Mach Theory 59:34-47

16. Tiwari SK, Joshi UK (2012) Stress analysis of mating involute spur gear teeth. In: International journal of engineering research and technology

17. Hewlett-Packard (1997, 26/06/2014) Order analysis. Available: http://www.home.agilent.com/upload

18. Fyfe K, Munck E (1997) Analysis of computed order tracking. Mech Syst Signal Process 11:187-205

19. Nikias CL, Mendel JM (1993) Signal processing with higher-order spectra. IEEE Signal Proc Mag 10:10-37

20. Saavedra P, Rodriguez C (2006) Accurate assessment of computed order tracking. Shock Vib 13:13-32 